\title{
A qualitative study of Ontario dairy farmer attitudes and perceptions toward implementing recommended milking practices
}

\author{
E. Belage, ${ }^{1,2}$ S. L. Croyle, ${ }^{1}$ A. Jones-Bitton, ${ }^{1}$ S. Dufour, ${ }^{2,3}$ and D. F. Kelton ${ }^{2 *}$ \\ ${ }^{1}$ Department of Population Medicine, University of Guelph, Ontario, Canada N1G 2W1 \\ ${ }^{2}$ Canadian Bovine Mastitis and Milk Quality Research Network, Saint-Hyacinthe, Quebec, Canada J2S 2M2 \\ ${ }^{3}$ Department of Pathology and Microbiology, Faculty of Veterinary Medicine, University of Montreal, Saint-Hyacinthe, Quebec, Canada J2S $2 \mathrm{M} 2$
}

\section{ABSTRACT}

Recommended milking practices (RMP) are protective against mastitis. However, many producers do not adopt, or only partially adopt, these measures. This study aimed to explore the attitudes and perceptions of Ontario dairy farmers toward barriers to implementation of RMP and to investigate what motivates behavior change in relation to milking hygiene. Four focus groups with Ontario dairy producers were conducted, and verbatim transcripts were analyzed thematically. The main barriers to adoption of RMP were identified and categorized into 2 groups: intrinsic barriers and physical barriers. Intrinsic barriers included personal habits and convenience, not perceiving udder health as a priority on their farm, and lack of information. Physical barriers included employee training and compliance, convenience of implementing RMP, and time, money, and labor barriers. Producers used their bulk tank somatic cell count (SCC) as a measure of perceived severity of udder health problems on farm. Those with lower SCC were less likely to prioritize udder health compared with peers experiencing elevations in SCC. Lack of udder health problems translated for some producers into non-adoption of certain RMP, as they felt these practices were not needed unless a problem arose. Others felt motivated to implement more practices and work toward better udder health if such efforts translated into rewards for better-quality milk. Some producers perceived RMP as not meaningful or useful, seemingly due to a lack of education about the reasons behind RMP implementation. Understanding the importance of these practices is one key to implementing them. To overcome some of the intrinsic barriers, increased efforts in knowledge translation are needed,

Received September 10, 2018.

Accepted May 18, 2019.

*Corresponding author: dkelton@uoguelph.ca including efforts in retraining current practices, as well as in establishing best practices.

Key words: mastitis, milking practices, barrier, attitude

\section{INTRODUCTION}

Mastitis (both clinical and subclinical) remains a considerable problem in Canadian dairies. For example, Olde Riekerink et al. (2008) reported the mean and median incidence of clinical mastitis in herds across all 10 Canadian provinces to be 23.0 and 16.7 per 100 cow-years respectively. Mastitis is one of the costliest diseases to the Canadian dairy industry: the average cost in terms of expenditures and production cost for clinical and subclinical infections was reported to be CAD $\$ 662$ (USD \$506) per milking cow per year (Aghamohammadi et al., 2018). Mastitis decreases farm productivity, and over $70 \%$ of economic losses from mastitis are accounted for by clinical mastitis (e.g., 24\% from discarded milk) and subclinical mastitis (e.g., $48 \%$ for lower milk production). Implementing preventative measures against mastitis accounted for $15 \%$ of the total cost (Aghamohammadi et al., 2018). Extensive reports in the literature have demonstrated that recommended milking practices (RMP) are associated with lower SCC, clinical mastitis incidence, and intramammary infection rates. Such practices include wearing gloves at the time of milking, using individual cow towels to wipe the udders, and using a post-milking teat disinfectant (Barkema et al., 1999; Dufour et al., 2012). Although these practices protect against mastitis, many producers still do not adopt, or only partially adopt, these measures (Steeneveld et al., 2014), despite their benefits being widely disseminated to producers. For example, the National Mastitis Council (NMC) created a 10-point recommended mastitis-control program based on research findings regarding RMP and published guidelines for producers to follow (these can be found online at https://www.nmconline.org/docs/ NMCchecklistInt.pdf). 
Dairy Famers of Canada (DFC) has established a set of recommendations for milking management and milk quality through the Canadian Quality Milk (CQM) program. This mandatory program requires farmers to have written standard operating procedures (SOP) for their milking protocols, to monitor and record use of antimicrobials and cow treatments to reduce the possibility of antimicrobial residue in milk, as well as to properly sanitize their milking equipment to ensure the highest level of milk quality (DFC, 2015). Under CQM guidelines, producers are required to "clean, sanitize and dry teats and use an approved teat sanitizing product and use it according to the label directions" (DFC, 2015). These are the only mandatory guidelines under the program. Producers are free to develop the rest of their milking protocols based on their needs or preferences. Previous Canadian research demonstrated significant variation in the level of adoption of the different recommended practices (Dufour et al., 2010). Furthermore, it was found that $27 \%$ of producers modified their milking procedures (i.e., implemented new practices, discontinued existing practices) in a 6-mo period (Dufour et al., 2010). Producers' behaviors and decisions to follow management guidelines or recommendations are influenced by several factors, including attitude, knowledge, opinion, beliefs, and skills (Leeuwis and van den Ban, 2004; Rehman et al., 2007; Pratt and Bowman, 2008).

Jansen et al. (2010) explored the perceptions and motivations among farmers in the Netherlands described as "hard-to-reach." This group of farmers was found to lack not necessarily the knowledge they needed to deal with issues such as mastitis, but rather the motivation or will to change. Researchers found that farmers lacked motivation when they perceived that the problem was not serious enough to need intervention (Jansen et al., 2010). The researchers also reported that behavioral change may be most improved by effectively communicating with each type of "hard-to-reach" farmer by tailoring the way information or advice is delivered, instead of using the same communication strategy with every producer (Jansen et al., 2010).

The objectives of this study were to explore the attitudes and perceptions of Ontario dairy farmers toward barriers for implementation of RMP, and to investigate what motivates behavior change in relation to milking hygiene.

\section{METHODS}

Approval for the study was obtained through the Research Ethics Board at the University of Guelph (REB\#15DC026), Ontario, Canada. All participants provided informed, written consent.
Four focus groups were conducted with dairy producers residing in southwestern Ontario, Canada, in April 2016. The sampling frame used for participant recruitment consisted of producers who participated in the Phase 1 Questionnaire of the National Dairy Study (NDS) 2015, who agreed to provide their contact information for further phases of the study and owned or leased milk quota in the province of Ontario. The locations for the focus groups were selected based on proximity to the largest number of dairy farms and having a driving distance from farms of less than 20 min.

All producers meeting the inclusion criteria were sent a recruitment letter and consent form describing the details and objectives of the study. Between 1 and 2 weeks later, participants were recruited via telephone. For each focus group, 8 to 10 producers were recruited, to help ensure a minimum attendance of 6 producers. A $\$ 100$ honorarium was paid to all participants for their participation.

A semi-structured questioning guide (Appendix Figure A1) was developed by the research team and then reviewed by 5 individuals who had experience working with dairy producers. The questions were designed to explore producers' perspectives on the relative importance and priority of mastitis (compared with all diseases and issues) on their respective farms, which milking practices they considered most important, in which situations they would consider making a change in their milking routine, their thoughts on barriers to implementing some of the RMP on their farms, and what would motivate them, and potentially other dairy producers, to make changes to improve udder health.

A trained moderator (a graduate student with previous experience in focus group methodology) facilitated all 4 focus groups, and an assistant made written notes of the discussion and group dynamics. Debriefing between the moderator and assistant was conducted immediately after the focus group. Field notes and audio transcripts were kept, to ensure reliability of the data and for audit purposes. Saturation was deemed to be reached when new data were redundant to data already collected (Creswell, 2013). Each focus group was approximately $90 \mathrm{~min}$ in length, audio-recorded, and professionally transcribed verbatim to facilitate analysis. Transcripts were double-checked against the original audio recordings for accuracy. Square brackets are used in quoted material to provide associated context. Each participant was given a unique identifier, created with a random letter representing the focus group and a number from 1 to 9 representing the participant (e.g., E3).

The data were analyzed using thematic analysis, as described by Braun and Clarke (2006) and using an inductive and deductive approach (Creswell, 2013). 
The primary author read and re-read the transcripts to immerse herself in the data. A research log was used to record notes and reflections from the focus groups and analysis of the data. Transcripts were coded using QSR International's NVivo 10 software, as follows: initially the data were coded line by line, then the codes were refined, and a codebook was assembled to define the meaning of each code. Transcripts were re-coded a final time using the codebook. Codes were then expanded and collapsed into themes, which were further refined to ensure they reflected the entirety of the data set (Braun and Clarke, 2006). These themes were then clustered into larger central themes. Themes were then refined and rearranged until a thematic map was found to accurately reflect the focus group discussions. Verbatim quotations were selected to highlight or illustrate the themes, following the guidelines of Corden and Sainsbury (2006). The Standards for Reporting Qualitative Research (SQRQ) guideline was used as the standard for reporting in this paper (O'Brien et al., 2014).

\section{RESULTS}

A total of 29 dairy producers (26 men and 3 women) participated in the focus groups. Herd size among participants ranged from 25 to 220 cows.
Two central themes were defined during analysis of the 4 focus groups: (1) barriers to adoption of RMP, and (2) motivations to improve udder health. The thematic map illustrating the themes and subthemes identified is shown in Figure 1.

\section{Theme 1: Barriers to Adoption of Recommended Milking Practices}

Participants' perceptions of barriers to adoption of RMP were classified into 2 central themes: intrinsic barriers and physical resources.

Intrinsic Barriers. Intrinsic barriers consisted of the following: (1) difficulty of changing habits and routines; (2) producer perception of a "good" SCC as an indicator of lack of udder health problems; (3) producer perception of mastitis as a problem on their farm and its priority relative to other issues on-farm; and (4) producer misconceptions or lack of information about RMP (Figure 1).

All focus groups identified habit and routine as an important part of milking management, both beneficially and as potential barriers to adopting RMP. For participants who were already implementing RMP, habits perpetuated proper milking hygiene. As a participant (S6) said, "It's like ABCs in school. It's so simple, strip,

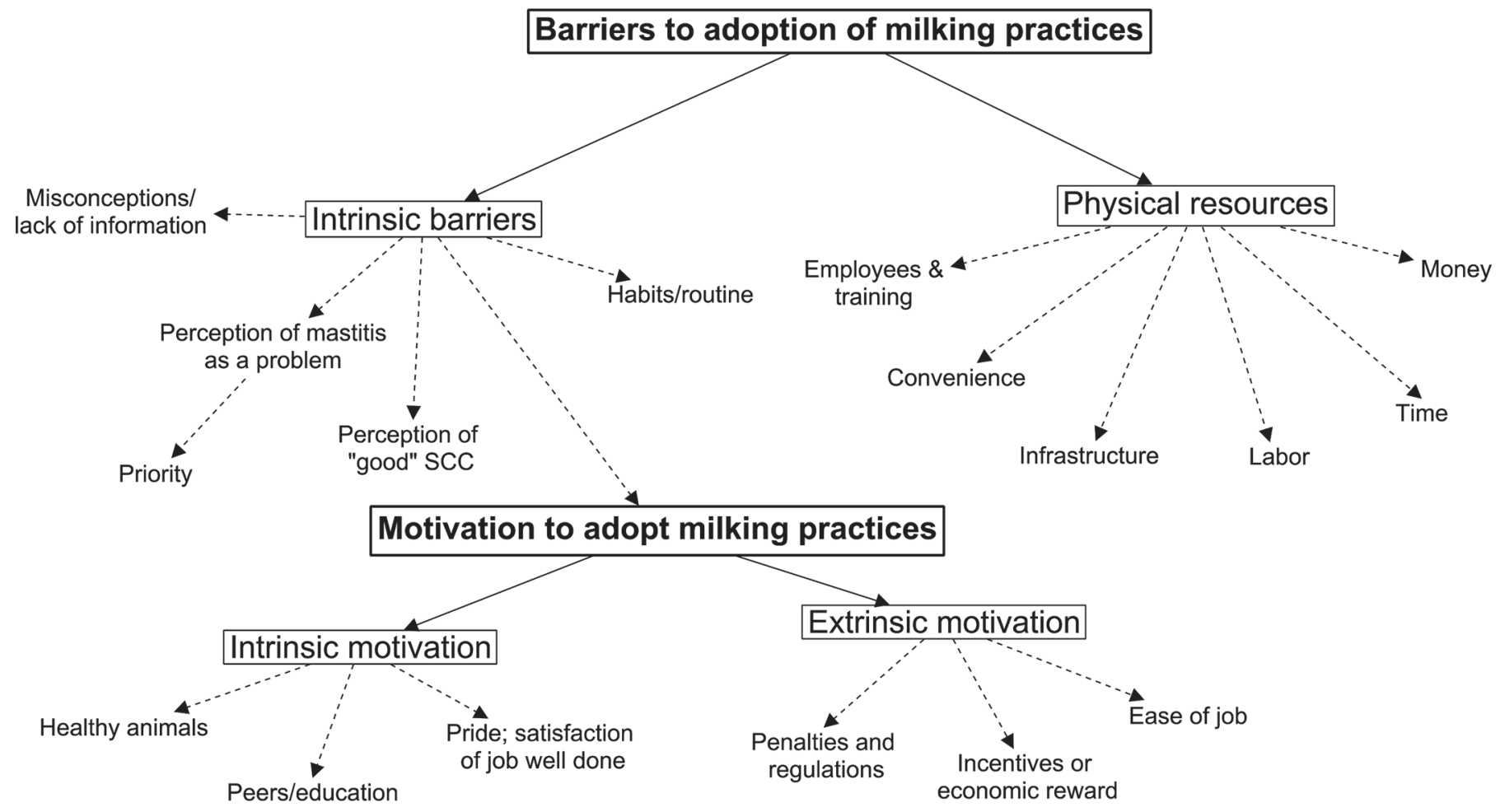

Figure 1. Thematic map of the perceived barriers and motivators for adoption of recommended milking practices (RMP), as produced from a thematic analysis of data collected during 4 dairy producer focus groups, conducted in Ontario, Canada (April 2016). 
wipe - dip well and wipe cleanly." However, for other participants who did not adopt RMP, habits and an established routine were a barrier to RMP adoption: producers milked their cows the same way for years, and it felt unnatural to change their procedures. Participants discussed how their personal routines worked for them, but they recognized that the same routines would not always work for other farmers. Different farm circumstances would therefore create varying degrees of implementation of RMP.

For participants who had hired employees, getting the employees to perform RMP as requested was one of the biggest hurdles. For example, one participant mentioned that training and educating each of his employees was the hardest part about changing his milking protocol. Participants described this being an even larger challenge for those employees who already had milking experience because it was hard to change previous milking habits. Participants also felt that bringing change into the routine and changing employees' routines was a barrier, and most of the time employees would go back to doing the routine the way they thought was best and not the way the employer wanted it. One participant expressed a wish for an educational tool such as a video, to make employee training easier.

Some producers did not perceive mastitis as a serious problem warranting changes to milking practices until their bulk tank SCC was above a certain threshold. Farmer W1 provided an example of this sentiment: "I don't wear gloves and my somatic cell's good, so I guess if I run into trouble I'd probably start looking for things to do." In this way, the prescribed 400,000 cells/ $\mathrm{mL}$ penalty acts as a barrier to following recommended practices. Some farmers stated that unused recommended practices would not be implemented so long as farmers were satisfied with their SCC scores. For example, one producer (W1) said that he had overheard another farmer saying, "if it's not in the penalty range I'm happy," and therefore would be unlikely to change his practices. Another participant (E1) similarly stated, "wherever the penalty level is, that's where some producers are going to be. Just as long as they're under, you don't care."

Milking practices are an important part of mastitis prevention; proper milking management is important to maintain good udder health in the herd. Participants were unlikely to incorporate additional RMP into their routine if they were not currently prioritizing issues concerning mastitis on their farm. Mastitis was viewed variably in terms of participants' priorities. To some, udder health was a very high priority because they felt that without good udder health, they would see more problems in other areas. These participants incorporated more RMP into their described SOP. Others did not prioritize mastitis prevention because it was not currently a problem on their farms, but they still perceived it as important.

Similarly, some participants did not perceive udder health as a concern, and this influenced their adoption of RMP: "If your somatic cell count is fine [under the penalty level], then don't worry about it [wearing gloves]" (K4), and "If it [the milking routine] ain't broke, don't fix it" (E5). Hence, producers did not always prioritize mastitis itself, but rather their SCC, and possibly also the penalty if it was close to the limit.

The reasons behind participants not adopting certain practices were also related to lack of knowledge or misconceptions about RMP. For instance, one participant discussed hearing peers not wanting to fore-strip during their milking routine, as they believed it causes more mastitis. Producer E1 felt that fore-stripping was a "waste of time." Other participants (E5, K3, K7, W7) further commented on the role of education on producers' not adopting RMP: although education might help a few producers change their habits, some people might still not be willing to get educated at all.

Similarly, some participants did not use glove disinfection, as they believed gloves were being disinfected throughout the milking routine via use of the pre-milking disinfectant or disinfecting wipes. Another example of why participants did not adopt RMP was the lack of information received from advisors: "I don't think any professionals suggested to do anything with gloves that I've talked to" (W5).

Physical Resource Barriers. Physical barriers included finances, time, labor barriers, infrastructure, convenience, and employees and employee training (Figure 1).

Participants felt that time and labor were significant barriers to adopting RMP. Participants E5, S2, S3, and K3 expressed that they did not want to spend more time milking than they already had to, as their days "were already long enough," and they "wouldn't be getting paid for the extra labor." Labor was also a challenge, especially for smaller operations where only one person was working (W1): "I run 60 cows by myself, labor is tricky, right? If you have an employee you can tell them how to do it and yeah you pay them an extra half an hour, and really, what does that add up to at the end of the year, probably not that much, right? But for me, I don't know, I want to get in the house and see my kids before 7:00, right? I don't want to be in the barn until 8:00 at night and they're in bed, because then there's no sense in farming, that's how I look at it."

Producers also mentioned financial barriers to adopting certain practices, especially the use of automatic takeoffs or expensive software, as the initial investment is quite large. At the same time, producers recognized 
that there is probably a payback in the long term for having these tools.

One of the reasons mentioned by participants for not adopting RMP was the convenience of the practice. Participants felt that including certain practices in their routine would not be convenient or would make their job harder (e.g., cows kicking, carrying strip-cup). Others mentioned changing their practices to make their routine easier, as by switching how they wiped cows' teats with disinfectant wipes versus a dip cup because carrying the cup was not as convenient.

Other participants felt they were not able to implement certain practices into their routines due to the current infrastructure on their farms or because they felt it would not otherwise work in their barn. Participants mentioned being willing to change or improve their routine, but they could not afford to make the large infrastructure changes deemed necessary to do so.

\section{Theme 2: Motivations to Improve Udder Health}

Participants described several factors that would motivate them or their peers to adopt RMP. These were categorized as intrinsic motivations and extrinsic motivations (Figure 1).

Intrinsic Motivations. Participants identified 3 factors that would intrinsically motivate them or their peers to improve udder health: pride and the satisfaction of a job well done; having healthy animals as a result of less mastitis; and the influence of their peers and education (Figure 1).

Participants felt that their own pride was a strong motivation to adopt RMP and achieve high udder health. One participant (E3) talked about the feelings of failure associated with not being able to ship some of the milk: "It makes you feel like you failed if you can't put that milk in the tank, you know. It's a bad day for you. Really, it is. What it comes down to: you don't feel good about what you did."

Several participants felt the reward of having healthy animals was a great motivation to improve udder health on their farms, and having healthy animals made their job easier. One producer (S2) also discussed how mastitis affected the animals in the long term, as some are more susceptible to recurrent cases of mastitis, and how preventing illness was a motivation to improve udder health: "it always seems that, not all cases, but whenever they have mastitis, it damages them for life. If you can avoid that, then you remove that possibility of being unhealthy."

The influence of successful peers motivated participants to improve udder health and follow recommended procedures. Most producers discussed being interested in listening and learning from successful operations.
There was widespread agreement within and between groups about the importance of peer influence in motivating change with respect to RMP. Other participants talked about the influence of producer meetings and producer ideas on their own management, and how gathering ideas from other farmers helped them transition to new management practices. In this way, farmers expressed that they learned proper milking protocols from each other, which created an environment that encourages the use of RMP. One participant (K5) talked about how increased awareness and knowledge would be a motivation to improve his udder health management: "I think it has to start with the farmer to know why. If I knew a better way to make the cows let their milk down better, I would do it, if it proved itself to be true, then we would do it." Another producer shared how participating in educational meetings motivated him to think back on his current practices and reevaluate them. Similarly, another producer discussed how remembering or being aware of the basics could influence his milking management.

Extrinsic Motivations. Participants listed penalties and regulations, incentives or economic rewards, and ease of job, as factors that would motivate them to adopt RMP (Figure 1).

Producers on our panels discussed penalties and the threat of being suspended from producing milk as motivators to adopt RMP to decrease SCC on their farm. One participant (S2) echoed this thought and said that if the marketplace required higher-quality milk or lower somatic cell count, producers would have to comply with consumer demand and "adapt or get out."

Another producer (E5) indicated that an economic incentive for lower SCC would strongly motivate him or other producers to adopt RMP: "If we'd be getting financial incentives for having our SCC average lower, I think we'd put in the effort, even though the numbers are actually dictating already that we are at an economic loss by battling with SCC." This thought was echoed by several other participants. Other producers perceived that there was already an economic advantage to implementing RMP, as having healthier cows and doing a better job would make a difference in their bottom line.

Participants discussed how making work easier was a motivation to adopt RMP to improve udder health. This sentiment was echoed by participants in other groups (R3): "fewer problems, there's something to be said for that."

\section{DISCUSSION}

Although physical barriers were an important limitation to the adoption of some RMP among participants 
in this study, this discussion will center primarily on the intrinsic barriers, as the latter are more difficult to address but can be targeted and reduced by the industry through knowledge translation and education.

Participants indicated that putting in the extra time and labor was difficult, as they felt they were already very busy with their operation. This was especially true for producers who already had low SCC; they felt little to no incentive to increase their workload via adoption of other practices. These findings are comparable to other studies in the field of Johne's disease management and implementation of control practices. For example, Roche (2014) found that a large barrier to producers' adopting Johne's disease control measures was a lack of time or money. Interestingly, many participants in the present study mentioned that they would be motivated by financial incentives to change their milking routines if it meant they achieved higher milk quality and they were given a premium for excellent-quality milk. Potentially, barriers to adoption of RMP could be overcome by the industry with the proper incentives. In the province of Quebec, premiums for milk quality were implemented in 2010: producers who achieved a bulk tank SCC of under 300,000 cells/mL were given a premium for their milk. That year, $81 \%$ of producers in the province got the premium (Producteurs de lait du Québec, 2010). The SCC threshold for receiving the premium was decreased to 250,000 cells $/ \mathrm{mL}$ in 2011 and to 200,000 in 2012 . In $2011,91 \%$ of producers received the premium (Producteurs de lait du Québec, 2011), $80 \%$ received it in 2012 (Producteurs de lait du Québec, 2012), and 75\% received it in 2013 (Producteurs de lait du Québec, 2013). Additional premiums were implemented in 2012 for producers with SCC under 150,000 cells/mL: $40 \%$ of producers received this additional premium in 2012, and $49 \%$ received it in 2013 (Producteurs du lait du Québec, 2013). Dairy producers did adjust to the premiums, even when these were more and more difficult to achieve, which shows a willingness to improve milk quality when financial incentives are provided. Other provinces might similarly benefit from milk quality incentives to see an improvement in udder health.

Although physical barriers will always be present and, to a certain extent, will prevent behavior change, it is the intrinsic barriers that may have the most effect on adoption or lack of adoption of RMP. Two theories of behavior change can be used to explain why recommended measures are not always adopted: the Theory of Planned Behavior and the Health Belief Model. Behavior is mediated by cognition; knowledge is necessary but not sufficient to produce behavior change. Perceptions, motivations, skills, and social environment are also key influences on behavior (NIH, 2005). In the present study, some participants' lack of adoption of RMP was due to lack of information on how to adopt RMP, but several participants were not willing to change milking routines already in place, especially if they already had good udder health and low SCC on their farm. These findings are similar to previous reports: in a study performed in the Netherlands, researchers found that producers' behavior was not dictated by a lack of information but rather a lack of motivation to change (Jansen et al., 2010). A way to mitigate this barrier is to tailor communication efforts to fit specific types of producers. For example, Lam et al. (2011) highlighted the importance of effective communication, which includes a "pro-active approach, personalization of messages, providing a realistic frame of reference for the farmer, and use of the farmer's social environment." Producers who have already achieved high-quality milk may not need to change their milking routines if they have a good protocol in place that has been working for them, but it could be a beneficial change for producers struggling with higher SCC on their farms. In this case, advisors need to provide producers with clear and updated information about RMP (e.g., the reasons behind the cleaning of gloves during milking, reasons for fore-stripping teats to check for abnormal milk). This is especially important for some producers and their employees, as the present study revealed that not all of them know the reasons behind proper milking preparation, and advisors may be assuming that they do.

Another important barrier to the adoption of RMP by producers was their perception of what "good quality" is and their perception of what is "good enough." Three constructs of the Health Belief Model, one theory of behavior change, may play a role in limiting producers' adoption of RMP: perceived susceptibility, perceived severity, and self-efficacy (NIH, 2005). Many of our participants felt motivated to find solutions when problems arise, but if there were no troubles with udder health, milking management stopped being a priority and tended to become an afterthought due to other competing farm concerns (perceived susceptibility). During the focus groups, most producers prioritized SCC as an indicator of susceptibility and severity of udder health. Those with lower SCC were less likely to prioritize udder health management on their farm compared with other diseases or issues. According to the Health Belief Model and the Theory of Planned Behavior, people will only take preventive action toward health risks once they perceive themselves as being susceptible (Janz and Becker, 1984). In this case, the perceived lack of a problem may drive the non-adoption of RMP. Dufour et al. (2012) showed that, on farms where producers "felt they were doing enough about mastitis control," cows had 3.1 times greater odds of 
acquiring Staphylococcus aureus intramammary infections. Not recognizing that contagious mastitis was a problem on their farm was perhaps the highest risk factor for $S$. aureus incidence.

The perception of what was deemed a "good somatic cell count" also seemed to vary among producers: those who considered a slight rise in SCC to be a problem, or who aimed to have as low an SCC as possible, were more likely to adopt RMP to find solutions (perceived severity). A possible explanation might be that some producers have concerns about changing their routine in a way that could lead to problems they do not currently have. The phrase, "if it ain't broke, don't fix it," was repeated several times during all the focus groups. This notion perhaps may extend to advisors as well, who may be afraid to make recommendations that could worsen the herd's current udder health.

Participants frequently commented how their own habits or routine held them back when it came to changing their behavior (self-efficacy). However, good habits and routines were also identified as an important part of milking routines, which indicates that further action should be taken to retrain bad habits and promote good habits. Previous research (Belage et al., 2017) demonstrated that producers were fairly consistent in their milking routines, regardless of whether they were correct or not. Recently, Animal Health Ireland introduced "Cell Check," a national mastitis-control program, and provided producers with training workshops and educational tools to retrain and establish best practices. Since the introduction of the program, the proportion of farms with an annual average SCC of over 400,000 cells $/ \mathrm{mL}$ has decreased by over $10 \%$ (McCoy, 2016). In contrast, the proportion of farmers with an annual average SCC under 200,000 cells/mL has increased by over 30\% (McCoy, 2016). This program shows how providing educational tools and workshops can help modify producer behavior, with a successful outcome. Another example of motivating behavior change took place in Quebec in 2010, where $32 \%$ of producers from the province participated in a training program ( $\mathrm{n}=2,043$; Poirier et al., 2011). Participating herds had higher linear scores than non-participating herds before training (2.92 vs. 2.86 , respectively; $t$-test $P<0.05)$ and experienced SCC improvements during a 10 -mo period following the training. Training programs therefore can have lasting effects in milk quality.

Many participants discussed how having employees adhere to a new protocol or a change in routine was a struggle. Although a range of producers discussed this barrier, it was most common to participants who owned larger herds and had multiple people milking cows. Participants emphasized the importance of educating their employees as to why certain practices are used during milking and expressed interest in tools or programs that would help educate their employees. A previous study highlighted the need to augment educational opportunities for employees on dairy farms in the United States (Erskine et al., 2015). In that study, employees were not familiar with the importance of certain management practices for mastitis prevention and control; this was also reflected in the present study. Potential training tools could be producer meetings, online videos, hands-on approaches, or a combined approach. These methods were effective at training producers for certain skills, such as performing a corneal nerve block before disbudding, as seen in the Winder et al. (2018) study. Online videos might be a great option for producers who are in remote locations or where veterinarians are not able to do regular herd health checks.

Lack of information was also an important barrier to adoption of RMP. Some participants did not seem to understand the reasons for certain practices. One producer even commented it was "a waste of time." However, RMP are widely disseminated in the industry by advisors and regulatory bodies. Understanding the importance of these practices is one of the keys to implementing them (NIH, 2005). Most importantly, certain RMP are mandatory (e.g., fore-stripping and inspecting milk) under the Canadian Quality Milk program, and penalties can be given to producers who do not follow the program. Perhaps penalties are not a strong enough motivator for adoption of RMP, and the industry should focus efforts on education, effective knowledge transfer, and implementing incentives for increased milk quality, as the latter was discussed as a very strong motivator for producers to improve udder health. The role of knowledge transfer and translation from research to farms was identified as important, as some third-party advisors and experts do not always agree on which practices are most useful, and producers are getting conflicting messages. Experts should be delivering a consistent message to producers to stimulate change.

\section{CONCLUSIONS}

Both physical and intrinsic barriers are important limitations to the adoption of RMP. Although some physical barriers can be addressed by motivating producers with incentives for high-quality milk, intrinsic barriers are harder to overcome, as they are linked to producer attitudes and perceptions. Producers may be motivated to implement RMP in their milking routine if they are given incentives for increased milk quality and lower SCC. Knowledge translation and education of producers and employees may also play a role in increasing adoption of RMP, as producers may be re- 
ceiving conflicting messages or may not be aware of the importance of implementing RMP in their milking routines.

\section{ACKNOWLEDGMENTS}

The authors thank all participating dairy farmers for their time and for making this research possible. This project was part of the Canadian Bovine Mastitis and Milk Quality Research Network program, funded by Dairy Farmers of Canada and Agriculture and AgriFood Canada through the Dairy Research Cluster 2 Program, Dairy Farmers of Ontario (Mississauga, ON, Canada), the Ontario Veterinary College (University of Guelph), and the Ontario Ministry of Agriculture, Food and Rural Affairs. The first author (E. B.) was also supported by an NSERC-CREATE in milk quality scholarship.

\section{REFERENCES}

Aghamohammadi, M., D. Haine, D. F. Kelton, H. W. Barkema, H. Hogeveen, G. P. Keefe, and S. Dufour. 2018. Herd-level mastitisassociated costs on Canadian dairy farms. Front. Vet. Sci. 5:100. https://doi.org/10.3389/fvets.2018.00100.

Barkema, H. W., J. D. Van der Ploeg, Y. H. Schukken, T. J. G. M. Lam, G. Benedictus, and A. Brand. 1999. Management style and its association with bulk milk somatic cell count and incidence rate of clinical mastitis. J. Dairy Sci. 82:1655-1663.

Belage, E., S. Dufour, D. A. Shock, A. Jones-Bitton, and D. F. Kelton. 2017. Adoption and consistency of application of pre-milking preparation in Ontario dairy herds. J. Dairy Sci. 100:3902-3911.

Braun, V., and V. Clarke. 2006. Using thematic analysis in psychology. Qual. Res. Psychol. 3:77-101.

Corden, A., and R. Sainsbury. 2006. Using verbatim quotations in reporting qualitative social research: Researchers' views. University of York, Social Policy Research Unit, York, UK. Accessed Mar. 3, 2019. https://www.york.ac.uk/inst/spru/pubs/pdf/ verbquotresearch.pdf.

Creswell, J. W. 2013. Research Design: Qualitative, Quantitative, and Mixed Methods Approaches. Sage Publications, Thousand Oaks, CA.

Dairy Farmers of Canada (DFC). 2015. Food safety reference manual. Accessed Sep. 1, 2017. https://dairyfarmersofcanada.ca/en/who -we-are/our-commitments/food-safety-canadian-milk-farm-table.

Dufour, S., H. W. Barkema, L. DesCoteaux, T. J. DeVries, I. R. Dohoo, K. Reyher, J. P. Roy, and D. T. Scholl. 2010. Development and validation of a bilingual questionnaire for measuring udder health management practices on dairy farms. Prev. Vet. Med. 95:74-85.

Dufour, S., I. R. Dohoo, H. W. Barkema, L. DesCôteaux, T. J. DeVries, K. K. Reyher, J. P. Roy, and D. T. Scholl. 2012. Manageable risk factors associated with the lactational incidence, elimination, and prevalence of Staphylococcus aureus intramammary infections in dairy cows. J. Dairy Sci. 95:1283-1300.

Erskine, R. J., R. O. Martinez, and G. A. Contreras. 2015. Cultural lag: A new challenge for mastitis control on dairy farms in the United States. J. Dairy Sci. 98:8240-8244. https://doi.org/10 $.3168 /$ jds.2015-9386.
Jansen, J., C. D. M. Steuten, R. J. Renes, N. Aarts, and T. J. G. M. Lam. 2010. Debunking the myth of the hard-to-reach farmer: Effective communication on udder health. J. Dairy Sci. 93:1296-1306.

Janz, N. K., and M. H. Becker. 1984. The health belief model: A decade later. Health Educ. Q. 11:1-47.

Lam, T. J. G. M., J. Jansen, B. H. P. van den Borne, R. J. Renes, and H. Hogeveen. 2011. What veterinarians need to know about communication to optimise their role as advisors on udder health in dairy herds. N. Z. Vet. J. 59:8-15.

Leeuwis, C., and A. van den Ban. 2004. Communication for Rural Innovation: Rethinking Agricultural Extension. 3rd ed. Blackwell Publishing Ltd., Oxford, UK.

Mc Coy, F. 2016. CellCheck-The Irish national mastitis control program. 6th IDF mastitis conference, Nantes, France, September 2016.

National Institutes of Health (NIH). 2005. Theory at a Glance: A Guide for Health Promotion Practice. 2nd ed. U.S. Department of Health and Health Services, National Cancer Institute, Washington, DC.

O'Brien, B. C., I. B. Harris, T. J. Beckman, D. A. Reed, and D. A Cook. 2014. Standards for reporting qualitative research: A synthesis of recommendations. Acad. Med. 89:1245-1251. https://doi .org/10.1097/ACM.0000000000000388.

Olde Riekerink, R. G. M., H. W. Barkema, D. F. Kelton, and D. T. Scholl. 2008. Incidence rate of clinical mastitis on Canadian dairy farms. J. Dairy Sci. 91:1366-1377.

Poirier, H., J. Durocher, R. Lacroix, J. Carrier, and D. T. Scholl. 2011. A coordinated udder health training strategy in Quebec, Canada. Pages 197-203 in Udder Health and Communication. H. Hogeveen and T. J. G. M. Lam, ed. Wageningen Academic Publishers, Wageningen, the Netherlands.

Pratt, C., and S. Bowman. 2008. Principles of effective behavior change: Application to extension family educational programming. J. Extension. 46:5FEA2. https://joe.org/joe/2008october/a2.php.

Producteurs de lait du Québec. 2010. Rapport Annuel 2010. Accessed Jul 5, 2019. http://lait.org/fichiers/RapportAnnuel/FPLQ-2010/ controleQualite.pdf.

Producteurs de lait du Québec. 2011. Rapport Annuel 2011. Accessed Jul. 5, 2019. http://lait.org/fichiers/RapportAnnuel/FPLQ-2011/ controle_qualite.pdf.

Producteurs de lait du Québec. 2012. Rapport Annuel 2012. Accessed Jul. 5, 2019. http://lait.org/fichiers/RapportAnnuel/FPLQ-2012/ qualite.pdf.

Producteurs de lait du Québec. 2013. Rapport Annuel 2013. Accessed Jul. 5, 2019. http://lait.org/fichiers/RapportAnnuel/FPLQ-2013/ controle_qual.pdf.

Rehman, T., K. McKemey, C. M. Yates, R. J. Cooke, C. J. Garforth, R. B. Tranter, J. R. Park, and P. T. Dorward. 2007. Identifying and understanding factors influencing the uptake of new technologies on dairy farms in SW England using the theory of reasoned action. Agric. Syst. 94:281-293.

Roche, S. 2014. Investigating the role of agricultural extension in influencing Ontario dairy producer behaviour for Johne's disease control. PhD Thesis. Department of Population Medicine, University of Guelph, Ontario, Canada.

Steeneveld, W., A. G. J. Velthuis, and H. Hogeveen. 2014. Short communication: Effectiveness of tools provided by a dairy company on udder health in Dutch dairy farms. J. Dairy Sci. 97:1529-1534.

Winder, C. B., S. J. LeBlanc, D. B. Haley, K. D. Lissemore, M. A. Godkin, and T. F. Duffield. 2018. Comparison of online, hands-on, and a combined approach for teaching cautery disbudding technique to dairy producers. J. Dairy Sci. 101:840-849. 


\section{APPENDIX}

"Okay, so just to get things going, I would like to go around the room and have everyone share their first name, where you farm, and what you enjoy most about being a dairy farmer."

"I would like to start our discussions today by talking about your attitudes and opinions toward managing udder health."

1. What comes to mind when you think about mastitis prevention in the industry?

- How important a problem do you feel mastitis is for the Ontario dairy industry?

- How does udder health rank in your priorities compared with other diseases?

- What do you think the economic impact of mastitis is on your farm?

EXERCISE: "I would like for you to think back to your milking routine and write on a piece of paper what practices you most commonly use on your farm." - "Now can you underline the 3 you think are most important?" 1 MINUTE

2. Would anybody like to walk me through your typical milking routine? (Pick 2 or 3 people.)

Remember there are no right or wrong answers, and everyone has different practices.

- Are any of these considered more important to you than others? (Probe: use of gloves and disinfecting, fore-stripping, predip, cleaning and drying teats, auto-takeoffs); strip and dip order.

- In which situations would you be likely to use any of these practices in your milking routine? (SCC problems, flare-ups of mastitis...)

- Have you changed your milking routine in the past? Would you change anything if, say, you had a higher incidence of mastitis cases or higher SCC count than previously?

- E.g., if changed from tiestall to freestall, how does protocol differ other than being a parlor?

3. When you think about implementing these recommended management practices on your farm, what do you see as the main barriers to adopting these recommendations?

- What do you think are some of the reasons you or other people are NOT implementing some of these into their milking routines?

- Employees, family, yourself?

-What kinds of barriers do you see for someone who hasn't done these?

- Probe further after time and money have been discussed.

- Can you think of potential solutions to address these barriers?

- Quota? Penalties? Education?

- Do you feel udder health could improve on some farms if we could remove these barriers?

"I would like to transition now to talk a little more generally about what motivates you to make changes on your farm and how you prefer to receive new information."

4. How do you think we can motivate producers to make changes to improve udder health?

- What motivates you to make any sort of change on your farm?

- How do the actions of your peers affect what you do?

Figure A1. Introductory script and questioning guide for focus groups. 
5. Think about the sources or people you use to get information on milking management decisions. What or who was the most influential when it came to designing your milking protocol?

- How did you develop your milking routine?

- Probe: neighbors, vet, magazines, peers, extension, family.

6. Is there anything you think is important about the implementation of milking practices on-farm that we haven't addressed?

Thank you all for coming; we appreciate your input and the time you took out of your busy day to come. Your participation and opinions are essential for this type of research. I would like to remind you that your statements will be anonymous in the final report. Please keep this session confidential by not talking about it after we leave today, to respect everyone's privacy that participated.

Please see Emilie to receive your compensation for participation, and please sign the receipt form before you leave.

Also feel free to help yourself to any coffee or snacks left. Thank you again.

Figure A1 (Continued). Introductory script and questioning guide for focus groups. 